\title{
Correction to: Aortic valve and coronary 18F-sodium fluoride activity: a common cause?
}

\author{
Rong Bing, MBBS, a and Marc R. Dweck, MD, PhD ${ }^{\mathrm{a}}$ \\ a BHF Centre for Cardiovascular Science, University of Edinburgh, Edinburgh, UK
}

doi:10.1007/s12350-019-01948-w

\section{CORRECTION TO: J NUCL CARDIOL}

HTTPS://DOI.ORG/10.1007/S12350-019-01901-X

The article "Aortic valve and coronary $18 \mathrm{~F}$-sodium fluoride activity: a common cause?', written by Rong Bing and Marc R. Dweck, was originally published electronically on the publisher's internet portal (currently SpringerLink) on 27 September 2019 with open access. With the author(s)' decision to step back from
Open Choice, the copyright of the article changed on 18 November 2019 to (c) American Society of Nuclear Cardiology 2019 and the article is forthwith distributed under the terms of copyright.

Publisher's Note Springer Nature remains neutral with regard to jurisdictional claims in published maps and institutional affiliations.
The original article can be found online at https://doi.org/10.1007/ s12350-019-01901-x.

Reprint requests: Rong Bing, MBBS, BHF Centre for Cardiovascular Science, University of Edinburgh, 47 Little France Crescent, Edinburgh EH16 4TJ, UK; rongbing.rb@gmail.com

J Nucl Cardiol 2020;27:1383.

$1071-3581 / \$ 34.00$

Copyright (c) 2019 American Society of Nuclear Cardiology. 